\title{
Saúde em prisões: representações e práticas dos agentes de segurança penitenciária no Rio de Janeiro, Brasil
}

\author{
Health in the prison system: representations \\ and practices by prison guards in \\ Rio de Janeiro, Brazil
}

\author{
1 Superintendência de Saúde, \\ Secretaria de Estado de \\ Administração Penitenciária \\ do Rio de Janeiro, Rio de \\ Janeiro, Brasil. \\ 2 Laboratoire de Psychologie \\ du Travail et de l'Action \\ Conservatoire National des \\ Arts et Métiers, Paris, France. \\ 3 Groupement de Recherche \\ et d'Études en Gestion à \\ $H E C$, Centre National de la \\ Recherche Scientifique, Paris, \\ France. \\ ${ }^{4}$ INSERM, UMR 707, Paris, \\ F-75012, France. \\ 5 Université Pierre et Marie \\ Curie-Paris 6,UMR-S707, \\ Paris, F-75012, France. \\ Correspondência \\ V. Diuana \\ Programa de Controle \\ da Tuberculose \\ Superintendência de Saúde, \\ Secretaria de Estado de \\ Administração Penitenciária \\ do Estado do Rio de Janeiro. \\ Estrada Guandu do Sena \\ 1902, Rio de Janeiro, RJ \\ 21854-010, Brasil. \\ vilmadiuana@gmail.com
}

\section{Abstract}

The role of prison guards in limiting access to health services by inmates and the impact of their representations on daily health practices were investigated through an action-research program. The program aimed to produce knowledge and improve the guards' involvement in tuberculosis and HIVIAIDS control by raising their awareness. Developed in three prisons and two hospitals, the study included individual interviews and group discussions and showed that representations of health and illness, risk hierarchy, and preventive strategies are related to actors' status in the prison's social organization, the conflicts and tensions between them, and the sense of group belonging that reinforces identities and antagonisms. Such representations have a major influence on the guards' daily practices and inmates' access to health services. The denial of inmates' right to health and their limited autonomy contributed to the implementation of essentially prescriptive health actions. The guards' awareness of their own health representations and practices may contribute to the deconstruction of stereotypes and increase their involvement in prevention and care. Further, improvement of inmates' health depends on changes in prison conditions.

Prisons; HIV; Tuberculosis
Vilma Diuana 1

Dominique Lhuilier 2

Alexandra Roma Sánchez ${ }^{1}$

Gilles Amado ${ }^{3}$

Leopoldina Araújo 1

Ana Maria Duarte 1

Mônica Garcia ${ }^{1}$

Eliane Milanez 1

Luciene Poubel 1

Elizabeth Romano 1

Bernard Larouzé 4,5

\section{Introdução}

O aumento da população encarcerada é fenômeno que vem sendo observado em numerosos países, industrializados ou não 1,2 , inclusive no Brasil 3. No Estado do Rio de Janeiro, que abriga atualmente cerca de 23 mil dos cerca de $400 \mathrm{mil}$ presos do país, esse crescimento foi de $45 \%$ entre 2002 e 2006 sem que houvesse a correspondente adequação da estrutura física e de pessoal, o que repercute no cotidiano das prisões. Condições precárias de higiene, celas mal ventiladas e superpopulosas abrigando mais de 50 indivíduos, como é o caso de algumas unidades do Rio de Janeiro, compõem o cenário mais freqüente. Essa situação contribui para o agravamento da condição de saúde dessa população que, oriunda na maioria das vezes de comunidades desfavorecidas, já apresenta estado de saúde precário antes mesmo do encarceramento 4,5,6,7 .

Nesse contexto, a disseminação de doenças contagiosas, em especial a infecção pelo HIV/ AIDS e tuberculose, constitui sério risco à saúde dos detentos, seus contatos (especialmente familiares e pessoal penitenciário) e para as comunidades nas quais irão se inserir após o livramento.

Os estudos sobre a saúde da população prisional brasileira são pouco numerosos, mas todos revelam situação grave no que refere à infecção pelo HIV e tuberculose 8,9,10, o que confirma a experiência cotidiana dos profissionais de saú- 
de. Assim, no Rio de Janeiro, estudo randomizado realizado no Sistema Penitenciário mostrou soroprevalência de HIV estimada em $4,8 \%$ entre os homens ( $\mathrm{n}=687)$ e $7,2 \%$ entre as mulheres (n = 304) ${ }^{10}$. Em 2002, estudo exaustivo de uma prisão masculina ( $\mathrm{n}=1.047)$ mostrou soroprevalência de 2,1\% 11. Em relação à tuberculose, em 2005 a taxa de incidência $(3.532 / 100 \mathrm{mil})$ foi, nas prisões do Rio de Janeiro, cerca de 35 vezes superior 12 à do Estado 13 , e estudos de rastreamento de casos por exame radiológico do tórax mostram prevalências entre $4,6 \%$ e $8,6 \% 14$, conforme as prisões estudadas. Entre os tuberculosos, a soroprevalência de HIV medida em uma das prisões foi de $14,6 \% 11$.

Ao contrário do que se poderia supor tendo em vista uma população fechada, aparentemente sob controle, são inúmeras as dificuldades para o desenvolvimento de ações de saúde nas prisões. Nesse ambiente onde a circulação de detentos é restrita e os profissionais de saúde evitam circular, os agentes de segurança penitenciária terminam por exercer um papel diferenciado no que se refere à regulação do acesso à saúde. Muitas vezes são os agentes de segurança penitenciária que julgam a necessidade de atendimento a partir do pedido do preso e atuam facilitando ou dificultando este acesso. Por outro lado, no ambiente confinado das prisões, estão em contato cotidiano e direto com os presos e expostos, como eles, aos riscos infecciosos, especialmente à tuberculose 15 . Por essas razões são atores privilegiados no que se refere a mudanças nas concepções e práticas de saúde nas prisões.

Essa situação privilegiada dos agentes de segurança penitenciária e o papel que eles podem desempenhar no âmbito da saúde nas prisões justificam o presente estudo, consagrado a suas representações e práticas em matéria de saúde.

\section{Contexto}

De acordo com Monteiro 16, diversos estudos no campo da saúde apontam para uma inter-relação entre práticas rotineiras de saúde, estilos de vida e condições econômicas, sociais e simbólicas da existência. Na prisão, as diversas representações e práticas relacionadas à vida, à saúde e aos riscos envolvidos no dia-a-dia resultantes de múltiplos discursos e práticas, inserem-se numa lógica peculiar que rege e organiza a vida nesta instituição.

Altamente hierarquizada, fundada no isolamento do exterior e no controle total sobre a vida dos sujeitos que aprisiona 17,18 , a prisão, esta instituição de confinamento forçado de grupos despossuídos e desonrados 19, promove a cons- tituição de dois grupos separados e antagônicos: os guardas, a quem cabe o controle e vigilância, e os detentos, que tentam escapar a este controle total de suas vidas 20 . Cada um desses grupos tende a conceber o outro por meio de estereótipos hostis, construindo seus papéis e suas identidades 21 com base nesta separação. Entretanto, não é apenas entre esses dois pólos que se constrói a dinâmica desse campo institucional. Entre os detentos, a convivência diária por longos períodos promove trocas e estabelece vínculos, propiciando a organização de grupos que funcionam com regras próprias e tornam ainda mais complexa a vida nesses estabelecimentos 22 .

Nessa situação de confinamento e restrição de liberdade, segundo um processo de adaptação à realidade carcerária, os conflitos e tensões entre os diversos atores impõem aos sujeitos uma tendência a dar a prioridade aos problemas ligados à segurança e à sobrevivência imediata para agentes de segurança penitenciária e presos, respectivamente, em detrimento das questões relacionadas à saúde. Estes sistemas de representação da realidade são estruturados não somente por uma avaliação "racional” mas também pelas características psicossociais produzidas pela situação de encarceramento 23,24. Eles refletem e reproduzem ainda a posição na hierarquia social ocupada pelos sujeitos e incidem sobre suas reações aos problemas e demandas que se colocam no dia-a-dia 25 , exercendo influência sobre a valorização dos sintomas, a busca por assistência, sobre o uso da medicação e, de maneira geral, sobre a implicação de agentes de segurança penitenciária e presos nas ações de saúde.

Assim, levantar e discutir os diversos discursos e representações envolvendo a saúde produzidos no espaço prisional a partir dos diferentes lugares sociais (detentos, agentes de segurança penitenciária, profissionais de saúde, professores, agentes religiosos e pessoal administrativo) adquire relevância por possibilitar a desnaturalização das representações e das práticas, e abrir possibilidades de novos agenciamentos.

\section{Método}

O estudo referente aos agentes de segurança penitenciária, cujos resultados serão apresentados neste artigo, faz parte de um programa de prevenção e assistência da tuberculose e da infecção pelo HIV em prisões. Trata-se de uma pesquisaação desenvolvida em três prisões (duas masculinas e uma feminina) e dois hospitais especializados (um de tuberculose e outro de HIV/AIDS). Neste artigo a análise se limitou às prisões masculinas. 
A escolha da pesquisa-ação 26,27,28 como método de abordagem fundamentou-se na possibilidade de produzir, ao mesmo tempo, conhecimento e mudanças. Tratava-se de articular atividade de produção de conhecimento e projeto de ação visando melhorar o acesso dos detentos ao serviço de saúde e, mais especificamente, às ações de controle e prevenção de DST/AIDS e tuberculose.

A hipótese de que as diversas representações relacionadas à vida, à saúde e aos riscos envolvidos no dia-a-dia sofrem, na prisão, o impacto das relações sociais e das formas de exercício do poder apontou a importância da conscientização e sensibilização dos diversos atores sociais quanto à compreensão da saúde como um projeto comum, que não pode ser alcançado individualmente, e a necessidade de mudança de comportamentos que consistem em barreiras a este acesso.

Nesta investigação, a ação designava tanto a aplicação de dispositivos técnicos concebidos dentro de uma ótica de prevenção e assistência como as atividades próprias do trabalho de análise capazes de contribuir para a sensibilização e tomada de consciência dos diferentes atores envolvidos no campo quanto às questões de saúde, seus modos de representá-las e suas práticas cotidianas. Seu alcance limitou-se às pessoas atingidas diretamente pelo trabalho e enfrentou a resistência da estrutura interna das prisões e sua inserção numa sociedade fundada na exclusão e na marginalização dos "criminosos" 19. A difusão dos conhecimentos produzidos nesse processo de pesquisa-ação é parte dessa busca pela conscientização e sensibilização dos atores sociais quanto à necessidade de mudar.

A equipe responsável pela pesquisa-ação era composta por dois psicossociólogos e um médico franceses, além de seis psicólogas, uma assistente social e uma médica brasileira, todas funcionárias do sistema penitenciário.

O trabalho de campo iniciou-se com a realização de entrevistas individuais semi-estruturadas com profissionais de saúde $(n=43)$, agentes de segurança penitenciária $(n=83)$ e presos $(n=65)$. Com base na análise do material colhido foram realizados grupos de discussão nas três unidades prisionais: três grupos exclusivamente com agentes de segurança penitenciária (um por unidade prisional) e 12 com agentes de segurança penitenciária e profissionais de saúde (quatro por unidade prisional). Nesses grupos foram abordados, além de temas específicos de cada unidade, um núcleo comum que englobava: a percepção e hierarquização dos riscos; as estratégias de proteção; a interação e as barreiras entre eles, os detentos e os diferentes grupos ins- titucionais; a circulação da informação; além das condições de vida e trabalho nas unidades (água, lixo, esgoto, comida espalhada, ratos...).

Assim, a opção por entrevistas individuais e grupos de discussão baseou-se na natureza das informações a serem colhidas. As primeiras, particularmente úteis no estudo das trajetórias individuais de acesso aos serviços de saúde, permitiram a apreensão fina de dados subjetivos referentes às representações, à experiência pessoal, assegurando a confidencialidade. Os grupos de discussão apresentaram a vantagem de liberar freqüentemente a palavra, permitindo compreender valores e representações partilhados, rituais, comportamentos e mecanismos de defesa coletivos frente a diversas situações. A articulação desses dois tipos de abordagem permitiu uma maior precisão nos diferentes planos desta pesquisa-ação, possibilitando maior segurança quanto às hipóteses formuladas e às decisões quanto às estratégias e abordagens do campo.

A análise do material obtido nas entrevistas individuais envolveu a construção de uma grade temática baseada nos três eixos de investigação definidos no projeto: (1) as representações dos riscos sanitários na prisão e as práticas associadas; (2) a influência do contexto e da cultura carcerária sobre o corpo, a saúde, o uso dos dispositivos sanitários, as estratégias de proteção dos diferentes atores; (3) a trajetória sanitária dos detentos. Esta grade detalhava sete grandes temas tratados nas entrevistas: (i) representação dos riscos sanitários na prisão, (ii) representação dos cuidados na prisão, (iii) imagens da prisão e dos diferentes atores sociais, (iv) prevenção, proteção, (v) experiência pessoal, (vi) práticas profissionais, (vii) propostas de mudança, de melhoramento, de ações.

A análise temática foi inicialmente realizada pelos pesquisadores que procederam as entrevistas, e posteriormente confrontada com as análises dos outros pesquisadores, por ocasião de reuniões periódicas realizadas para este fim.

Cada entrevista foi tratada individualmente e dividida em função dos temas citados acima. Posteriormente, os elementos temáticos extraídos de cada uma delas foram reagrupados segundo os sete temas já mencionados, permitindo a reconstituição do conjunto do discurso sobre de cada tema. Comparou-se então o que estava em acordo e o que estava em desacordo e buscou-se pistas nas entrevistas que permitissem elaborar hipóteses explicativas destas diferenças, que, assim trabalhadas se mostraram reveladoras de outros fatores intervenientes.

Essa metodologia possibilitou identificar os temas dominantes, realizar análises comparativas das representações e práticas dos diversos 
atores envolvidos e construir hipóteses orientadoras da investigação. Estas, conforme Thiollent 28, consistem numa suposição formulada pelo pesquisador a respeito de possíveis soluções para problemas colocados pela pesquisa no nível observacional e cuja comprovação permanece aberta à argumentação e ao diálogo entre os interlocutores, com cotejamento dos diferentes saberes.

Durante o desenvolvimento da pesquisa foram realizados cinco seminários conjuntos entre as equipes francesa e brasileira. Esses seminários tinham por função expor, discutir e analisar o material produzido no campo, elaborar hipóteses, formular propostas e tomar decisões acerca do processo de investigação. Este processo de produção de conhecimento, que se fundamenta na perspectiva dialógica e argumentativa, encontra sua elucidação na transformação da situação ou na tomada de consciência dos obstáculos à mudança. Trata-se, de acordo com Thiollent 28 , de um processo de particularização do conhecimento que passa do geral ao concreto, sob a forma de diretrizes e comprovações argumentadas.

Reunir os agentes de segurança penitenciária não foi tarefa fácil em razão da impossibilidade de se afastarem simultaneamente de seus postos durante o horário de trabalho e pelo desinteresse em permanecer na prisão após o término de seu plantão. Para tornar essa atividade atraente optou-se por um dispositivo grupal que denominamos "café da manhã". Realizados no horário das trocas de plantão, este espaço de convívio visava a criar oportunidade de reunir de forma livre tantos os agentes de segurança penitenciária que chegavam quanto os que deixavam o trabalho. Esses grupos de discussão, totalmente incomuns no contexto das prisões do Rio de Janeiro, foram muito bem aceitos e contaram com grande participação dos agentes de segurança penitenciária, atraindo inclusive profissionais de saúde, assistentes sociais, psicólogos e o diretor de uma das prisões. Esse dispositivo grupal produziu, como um de seus efeitos, a demanda de continuidade dessa atividade e a criação de um espaço de comunicação e troca sobre temas de saúde. Proporcionou ainda um rico aprendizado e ofereceu elementos valiosos à reflexão sobre metodologia de ação em contexto carcerário.

Este estudo foi aprovado pelo Comitê de Ética em Pesquisa da Escola Nacional de Saúde Pública Sergio Arouca, Fundação Oswaldo Cruz (ENSP/ FIOCRUZ) e Comissão Nacional de Ética em Pesquisa. A confidencialidade das informações foi assegurada por meio da codificação das entrevistas preservando-se a identidade dos entrevistados.
Neste artigo serão apresentados somente os resultados que concernem às concepções de saúde, aos riscos sanitários e às estratégias de prevenção e preservação da saúde mobilizados por agentes de segurança penitenciária nas relações com os demais atores sociais em suas práticas cotidianas na prisão, bem como suas repercussões para sua própria saúde e a dos detentos.

\section{Resultados}

\section{As relações sociais e a percepção dos riscos sanitários}

A análise das entrevistas individuais, considerando a hierarquização dos riscos sanitários, mostrou que, no discurso dos agentes de segurança penitenciária a ameaça à sua integridade pessoal aparece como inerente ao trabalho e torna-se presente por meio da constante referência à tensão emocional, às diversas manifestações psicossomáticas, ao estresse ou aos meios utilizados para atenuá-lo, em especial o álcool.

"Existe um índice muito grande de alcoolismo (...) É um círculo vicioso. O serviço não é agradável, a tensão é muito grande para o agente penitenciário. $O$ nosso serviço tem uma rotina que não é qualquer um que agüenta. Quem não participa disso, já tem problemas de alcoolismo, imaginem nós! Depende também do nível social. Alguns saem daqui e conseguem se desligar (...) Quem faz bico, não pode estar alcoolizado, então fica mais sóbrio por algum tempo" (agente de segurança penitenciária).

Para os presos esta percepção do risco à sua segurança também é uma constante: "Meu maior medo é não chegar à rua. Eu queria conseguir chegar lá. Procuro fazer por onde que não aconteça" (detento). Esta preocupação com a integridade física aparece associada a seus pertencimentos grupais, lealdades e confrontos existentes entre eles: “A facção daqui não permite um homossexual ter relação com outro. Outras facções permitem. Aqui é perigo de perder o pescoço" (detento). Relaciona-se também às pressões geradas pela disciplina e punições aplicadas pela administração através dos agentes de segurança penitenciária: "Porque se tivessem um pouco mais de cuidado (...) Nós erramos, mas ele também não tem direito de fazer isso, sair quebrando tudo, jogar fora o remédio que a família trouxe" (detento).

Para os integrantes dessas duas categorias, os riscos à integridade pessoal encontram-se no topo das preocupações e estão fortemente marcados pelas relações formais e informais que regulam a vida na prisão, fazendo com que a apreensão quanto aos demais riscos à saúde 
fique relegada ao segundo plano. Isso acaba por repercutir na avaliação que fazem dos riscos por doenças, bem como na recepção das mensagens informativas e preventivas relativas às moléstias contagiosas.

No entanto, as referências às doenças ligadas à sujeira-leptospirose, micoses, sarna, parasitoses e infecções bacterianas - também se encontram presentes tanto na fala de agentes de segurança penitenciária como de presos, associadas às condições de vida ou de trabalho do ambiente prisional e à falta de condições e meios de higiene pessoal (detentos) e coletiva. Tanto uns quanto outros são confrontados com a impotência perante o sujo e o tóxico que aparecem como algo imposto e que, interiorizado, contamina as identidades associando-as ao lixo e ao sujo, àquilo do qual se quer distância. "Nós mesmos convivemoscom tanta sujeira que corremos o risco de nos acostumar com ela" (agente de segurança penitenciária).

Além das doenças que associam à sujeira, também são percebidas como riscos à saúde a tuberculose e demais "doenças do pulmão", a hepatite e a AIDS, nesta ordem, tanto por presos quanto por agentes de segurança penitenciária. Como mal contagioso, são consideradas como ameaças produzidas pelo contato, pelo compartilhamento forçado do espaço, pela convivência obrigatória, pelo confinamento, e favorecem o sentimento de exposição a uma possível contaminação que pode entender-se do plano sanitário ao das identidades, do âmbito dos corpos ao psíquico e ao moral. Para os agentes de segurança penitenciária, a experiência da confrontação com o vírus e as doenças no exercício profissional vem confirmar o imaginário: a concretização da ameaça que representa a relação com os detentos. "Os presos vivem confinados e o agente tem contato direto com eles. No frio eles pegam resfriados e outros ficam com tuberculose e a gente em contato (...) O meu medo é esse. Não se sabe o que ele tem" (agente de segurança penitenciária).

Desse modo, embora seja possível observar uma base comum quanto aos riscos sanitários percebidos pelos dois grupos sociais enfocados neste estudo, ainda assim a saúde não é percebida por eles como um ponto de convergência que permita reduzir a distância que os separa. Os processos de categorização e de discriminação social sempre pregnantes no ambiente prisional 17 constituem fatores estruturantes de seus sistemas de representação social, e incidem na percepção e na significação que os agentes de segurança penitenciária atribuem às doenças e às práticas de proteção e preservação da saúde.

As doenças, ao inscreverem-se na lógica prisional, suscitam medidas defensivas/práticas de proteção que, encontrando sua matriz na separa- ção “nós” (guardas) / “eles” (detentos) provenientes das relações hierárquicas e assimétricas da prisão, retornam sobre os sujeitos reafirmando as identidades 29 e fixando papéis. Tais medidas consistem em:

- Identificar os doentes: os presos são vistos como os principais transmissores de doença. Os homossexuais em especial, no caso da AIDS.

- Manter distância dos presos: principalmente daqueles identificados como doentes.

- Prender a respiração ao entrar nas celas ou ao abrir o camburão: último recurso para manter a separação e impedir a penetração do mal, tanto no plano do corpo como no das identidades.

Essas medidas defensivas baseadas em premissas equivocadas, além de ineficazes, acabam por contribuir para aprofundar ainda mais a distância e dificultar o convívio já difícil entre agentes de segurança penitenciária e detentos.

No caso da AIDS, a forma de transmissão - troca entre indivíduos por meio do sexo e do sangue - parece ajustar-se às medidas defensivas utilizadas. A identificação e o afastamento dos doentes e dos "suspeitos" (os presos, em especial os homossexuais), a quadriculação do espaço prisional (lugares de presos/“lá dentro" e lugares de agentes de segurança penitenciária/"aqui fora”) e a separação "nós"/agentes de segurança penitenciária e "eles"/presos (guarda não tocar em preso) parecem proporcionar a impressão de um risco sob controle.

Para os agentes de segurança penitenciária, esse risco só parece adquirir relevância quando referido à permanente tensão entre eles e os presos, "que podem utilizar as doenças como armas" ("tossem na cara do guarda" e "ameaçam com sangue") ou no caso em que têm de "separar briga entre eles". Nesses casos, o risco de contato com sangue ameaça romper as barreiras que os separam, trazendo consigo a angústia que acompanha a quebra das defesas muito sedimentadas. Já a tuberculose, por sua propagação pelo ar, se contrapõe às tentativas de demarcação territorial e constitui indistintamente uma ameaça a todos, fragilizando a categorização defensiva "nós"/ "eles" e contaminando as identidades. "Nãoépossível deixar de respirar", "se prendo a respiração, quando volto a inspirar o ar entra com mais força e o risco é maior" (agente de segurança penitenciária). Como se defender do ar que entra e sai do interior de cada um, revelando a fragilidade da separação que a fixação das identidades parece garantir? Como se defender desta reciprocidade que nenhuma hierarquia pode proibir? Dessa forma, pode-se entender por que a tuberculose apresenta-se como a doença mais ameaçadora não só entre os detentos, mas também entre eles e os agentes de segurança penitenciária, e por 
que seu controle passa necessariamente por um questionamento dos papéis e das identidades fixas ${ }^{21}$ produzidas pela condição de encarcerado ou pela situação de custodiador.

\section{O acesso à saúde e a ordem disciplinar}

O acesso à saúde está atravessado pelas representações sociais que informam as representações e as práticas. A imagem que os agentes de segurança penitenciária mantêm acerca das pessoas presas fundamenta uma desvalorização das queixas que estes últimos manifestam quanto a seu estado de saúde. Muitas vezes percebidos como incapazes, indolentes e dissimulados, os presos não são considerados como interlocutores confiáveis. É preciso que apresentem sintomas verificáveis. O sofrimento psíquico parece não ser percebido como motivo suficiente para suscitar a assistência à saúde ou para evidenciar que algo não vai bem.

A desvalorização do preso e de sua queixa é acompanhada de uma avaliação informal da demanda de assistência por parte dos agentes de segurança penitenciária, o que acaba por resultar em uma modulação do acesso ao serviço baseada em critérios estranhos à saúde. A influência desses fatores se mostra matizada pelo papel que as lideranças de grupos de detentos (em alguns casos determinados por facções) exercem no que concerne à assistência e aos cuidados de saúde.

A concepção da saúde como um direito dos presos independentemente do mérito e da disciplina, embora formalmente reconhecida pelos agentes de segurança penitenciária, aparece cercada de uma fala ambivalente. "O preso da facção ' $X$ ' é mais agradecido à pessoa, já o de facção ' $Y$ ' acha que o Estado tem obrigação de atender. Com a facção ' $Y$ ' a gente não faz mais que a obrigação. Eu digo pra eles: 'Tenho que zelar por vocês, mas não vamos abusar também"' (agente de segurança penitenciária). Nessa perspectiva, para que a oferta/demanda de saúde possa funcionar dentro das prisões, ela precisa estar inscrita numa relação de dívida e gratidão que permita negociações que restabeleçam as precedências, garantindo a adesão dos detentos aos valores hierarquizantes. Esta tensão entre diferentes valores e estratégias defensivas da identidade adotadas por detentos e agentes de segurança penitenciária parece manifestar-se na prisão em todos os domínios da vida.

Submetida à ordem disciplinar, a saúde, além de funcionar como elemento de troca e negociação para manutenção da ordem e da disciplina no cárcere, também é considerada pelos agentes de segurança penitenciária como instrumento de "recuperação" dos detentos, inserindo-se na lógica da "modelagem" dos sujeitos 20. "Eles [os presos] precisam dos profissionais de saúde, terapeutas e assistentes sociais para recuperálos" (agente de segurança penitenciária). Dessa forma, os agentes de segurança penitenciária tentam atribuir aos outros técnicos os cuidados com os detentos, procurando reter para si próprios apenas o aspecto da vigilância e da segurança envolvido na custódia. Assim poderiam solucionar as contradições entre as intervenções necessárias para vigiar e aquelas dirigidas a assistir/prevenir, já que estas últimas pressupõem uma aproximação do preso desde um lugar diferente daquele do treino, do adestramento e da disciplina.

Esta separação entre agentes de segurança penitenciária e presos insere-se na lógica das estratégias defensivas das identidades. Isso é explicitado quando, por exemplo, os agentes de segurança penitenciária não tomam a iniciativa de conduzir os detentos ao serviço de saúde, salvo quando solicitados pelos próprios presos, uma vez que isto poderia acarretar "problemas para o interno", que seria visto com desconfiança pelos outros presos, como "amigo de guarda". Além disso, "encaminhar o preso seria motivo de chacota" [deboche] entres agentes de segurança penitenciária, pois "existe uma barreira psicológica entre o preso e o agente". "Eles [os presos] parecem entender apenas a linguagem da ignorância e o guarda que não age dessa forma passa a ser visto [pelos presos] como 'guarda bombom'” (agente de segurança penitenciária). No contexto das relações agente de segurança penitenciária/detento, o cuidado aparece como fraqueza, como sinal de rebaixamento e submissão, inaceitável para a manutenção da imagem de "força" e "poder" reivindicada pelos dois pólos desta interação.

Desse modo, a estrutura e as relações sociais entre os diferentes grupos no interior das prisões promovem a construção de representações que modulam o acesso aos serviços sanitários.

\section{Discussão}

Ainda que os agentes de segurança penitenciária desempenhem, juntamente com os presos, importante papel na vida cotidiana das prisões, sua implicação no campo da saúde poucas vezes foi estudada 30 . Os presos habitualmente são considerados como indivíduos submetidos à ordem carcerária a quem é negada a condição de paciente 30 . A resistência por parte dos agentes de segurança penitenciária, da administração penitenciária e da sociedade em geral em considerar a saúde como um direito das pessoas presas, associada à prevalência das questões de seguran- 
ça, acabam por produzir ações de saúde eminentemente prescritivas.

Em contraste com a maior parte dos estudos desenvolvidos nesse meio, a pesquisa realizada não se limitou à coleta de dados, difusão de informação e distribuição de material educativo. Ela permitiu, sobretudo, a criação de um espaço de reflexão e trocas entre os diversos atores que integram a vida carcerária que, na maioria das vezes, exercem suas atividades de forma isolada.

Ao escolher os entrevistados, procurou-se construir uma rede que levasse em conta a relevância dos informantes e que considerasse sua importância para a difusão, aceitação e envolvimento no processo de pesquisa-ação, a partir de sua representatividade qualitativa. Segundo Thiollent 28 (p. 63), este tipo de amostra intencional "é dada por uma avaliação da relevância política dos grupos e das idéias que veiculam dentro de certa conjuntura ou movimento". Trata-se de chegar a uma "representação de ordem cognitiva, sociológica e politicamente fundamentada, com possível controle ou retificação de suas distorções no decorrer da investigação". Este foi um dos pontos considerados: a necessidade de adequação ao funcionamento real do sistema de cuidados em cada uma das prisões, de modo a enfrentar da melhor maneira possível as dificuldades deste tipo de pesquisa em um meio fechado e hierarquizado como o das prisões.

Ao provocar a discussão das diferentes concepções quanto aos riscos de contágio e as modalidades de proteção frente às doenças infecto-contagiosas mobilizadas por ocasião das atividades profissionais que desempenham, esta pesquisa possibilitou confrontar os diversos sistemas de representações envolvidos nas práticas cotidianas de saúde dos agentes de segurança penitenciária e promoveu a desconstrução de algumas idéias estereotipadas associadas à representação dos detentos como a "fonte do mal" 31, nas quais baseiam suas reações diante dos problemas de saúde apresentados no contexto particular da vida carcerária.

A análise da priorização dos riscos sanitários mostrou que, no discurso dos agentes de segurança penitenciária, a ameaça à sua integridade pessoal aparece como inerente ao trabalho e associa-se às relações hierárquicas, formais e informais, que regulam a vida na prisão. Tal achado é consistente com pesquisas realizadas na Bahia 15 e no Rio de Janeiro 32 com agentes de segurança penitenciária que também apontam o estresse e o sofrimento psíquico ligados à incerteza e insegurança no trabalho como principais questões de saúde desta categoria profissional.

Ao propiciar a discussão de temas de saúde relacionados à execução de suas atividades como a tosse dos detentos durante o confere, a manipulação dos objetos de uso pessoal dos presos durante as revistas gerais e o contato com sangue nas situações de conflito entre presos e presos e entre presos e guardas, promoveu maior implicação dos agentes de segurança penitenciária com as questões de saúde e permitiu que refletissem sobre a necessidade de ações especificamente voltadas para este grupo. Revelou ainda a falta de integração com os profissionais de saúde que atuam nas unidades prisionais, apontando para importância de um trabalho conjunto com os diferentes segmentos institucionais (saúde, educação, segurança) não apenas no momento da execução como também na definição, planejamento e organização das ações de saúde. Assim como foi apontado no estudo baiano já citado 15, os agentes de segurança penitenciária não têm participado de decisões gerenciais que, no entanto, implicam mudanças diretas em sua prática. Isso repercute neles como desvalorização e abandono por parte da administração.

As observações realizadas no transcorrer do trabalho sugerem, portanto, que qualquer transformação da realidade dos sujeitos e a melhoria da prevenção e da assistência à saúde nas prisões precisa levar em conta tanto as condições de organização e estruturação material e social da prisão quanto a dimensão simbólica das práticas dos diversos atores sociais envolvidos e sua interação, 33 apontando para ações menos prescritivas que permitam maior participação de presos, agentes de segurança penitenciária e de outros atores que integram a vida no cárcere. Os princípios gerais para o controle do HIV e da tuberculose são bem definidos. O grande desafio é fazer com que as estratégias de luta sejam adaptadas à realidade das diferentes prisões pelos próprios atores do sistema carcerário segundo um processo aplicável a outros contextos carcerários no Brasil e no exterior.

Diversas dificuldades foram encontradas no curso desta pesquisa-ação para a manutenção, ampliação e consolidação destes espaços de interlocução entre agentes de segurança penitenciária e profissionais de saúde, revelando que os princípios da ordem carcerária, a hierarquização das relações sociais, os conflitos e tensões gerados pelo controle de uns sobre outros, e até mesmo os locais, horários, plantões e regimes de trabalho funcionam como obstáculos estruturais à pretensão de criar espaços de reciprocidade $\mathrm{e}$ trocas tendo a saúde como base comum.

Revistas gerais nas celas, transferências, "fechamento da cadeia", suspensão de visitas e outras medidas administrativas que expressam a violência institucional que caracteriza as relações sociais na prisão pontuaram todo o desenvolvi- 
mento da pesquisa. Por outro lado, o controle da fala e do comportamento dos detentos por lideranças e grupos informais ou mesmo a recusa por parte de alguns deles em atender a convites da equipe da pesquisa para participar evidenciaram sua descrença na possibilidade do diálogo como forma de interação com uma administração que lhes nega a escuta e lhes restringe a autonomia. Esta falta de autonomia também já foi apontada por Condon et al. 34 como um dos maiores obstáculos para assegurar que as necessidades de saúde dos detentos sejam contempladas.

O endurecimento da política de segurança e a agudização dos conflitos entre presos e agentes de segurança penitenciária que ocorreram no Sistema Penitenciário do Rio de Janeiro durante o curso deste estudo, limitaram fortemente as possibilidades de transformação da realidade das pessoas integrantes da comunidade carcerária. Durante esse período ocorreram rebeliões e greves de fome acompanhadas de revistas gerais e transferências de detentos de uma unidade para outra. Tentativas por parte da administração penitenciária de quebrar a ordem informal de organização dos prisioneiros e reações a esta política aumentaram a sensação de insegurança nas prisões, tanto entre presos e guardas como entre profissionais de saúde que, pela primeira vez no estado, ficaram reféns em uma penitenciária controlada por presos rebelados. Nesse período, mudanças na estruturação do sistema penitenciário reduziram a importância da saúde em favor de políticas duras de controle do cárcere 35 , ocasionando o desmantelamento dos programas de saúde que contemplavam ações de prevenção, reduzindo-os apenas a seus aspectos curativos. Recentemente surgiram novas perspectivas que poderão permitir, especialmente para a tuberculose, a implementação de programas baseados na pesquisa-ação relatada neste artigo.

\section{Conclusões}

A prisão, como conjunto significativo, organiza as percepções e representações de risco de detentos, guardas, profissionais de saúde e demais atores sociais participantes da vida carcerária. Para eles, as representações das doenças inscrevemse numa hierarquia de riscos em que sobressaem os perigos de morte violenta, de agressão, de humilhações, ou mesmo de desvalorização de si, relegando a um segundo plano a percepção das doenças e dos cuidados com a prevenção e a recuperação da saúde.

As imagens e visões que cada grupo constrói em relação aos demais refletem e reproduzem sua posição na hierarquia social e incidem sobre sua reação aos problemas e demandas que se colocam no dia-a-dia. As percepções e representações de risco que orientam as ações dos diferentes grupos e sujeitos que integram a vida no cárcere podem se constituir em barreiras às ações de saúde.

A falta de dispositivos legitimamente reconhecidos que possibilitem trocas e processos de reciprocidade entre os diferentes atores parece contribuir para a limitada participação e pequeno envolvimento de funcionários e de detentos nas ações de prevenção e assistência. A boa resposta dos agentes de segurança penitenciária ao trabalho faz supor que a descrença, o sentimento de abandono e de desvalorização dos profissionais que atuam nas unidades pode ser reduzido por um trabalho que contemple a escuta e a construção conjunta de soluções que possam ser assumidas pelo grupo. No entanto, uma transformação mais duradoura das concepções e práticas de saúde no sistema penitenciário requer ações que ultrapassem os muros da prisão e possibilitem o questionamento dos diferentes sistemas simbólicos que dão suporte para a segregação, negação de direitos 10 e restrição da autonomia das pessoas privadas de liberdade.

"Para que o sujeito se constitua como tal, é necessário que, antes de tudo, o outro lhe dirija a palavra, lhe invista, o nomeie, o reconheça e lhe atribua um lugar, um sentido enquanto possibilidade" 36 (p. 26). 


\section{Resumo}

O papel limitante dos agentes de segurança penitenciária no acesso dos detentos aos serviços sanitários e o impacto de suas representações e práticas de saúde no cotidiano prisional foram objeto de pesquisa-ação visando tanto à produção de conhecimento como à melhoria das ações de controle da tuberculose e HIVIAIDS pela participação e conscientização. Desenvolveu-se em três prisões e dois hospitais por meio de entrevistas individuais e grupos de discussão. Revelou que concepções de saúde e doença, hierarquização de riscos e estratégias de preservação no contexto carcerário relacionam-se às posições nessa organização social, aos conflitos e tensões ali existentes e aos pertencimentos grupais que reforçam identidades e antagonismos, refletindo-se nas práticas rotineiras e no acesso aos serviços. A negação da saúde como um direito dos presos e a restrição de sua autonomia contribuem para ações de saúde prescritivas. A tomada de consciência dos agentes de segurança penitenciária quanto às representações e práticas de saúde pode contribuir para a desconstrução de idéias estereotipadas e aumentar seu envolvimento nas ações de prevenção e assistência. A melhoria das condições de saúde dos detentos implica também mudanças nas condições de encarceramento.

Prisões; HIV; Tuberculose

\section{Colaboradores}

V. Diuana, D. Lhuilier, A. R. Sánchez, G. Amado e B. Larouzé participaram da concepção, desenho do estudo, análise, redação e revisão do manuscrito. L. Araújo, A. M. Duarte, M. Garcia, E. Milanez, L. Poubel e E. Romano realizaram o trabalho de campo e participaram na análise.

\section{Agradecimentos}

Agence Nationale de Recherche sur le Sida, França (programa $n^{\circ}$. 1.283).

\section{Referências}

1. International Center for Prisons Studies, King's College London. World prisons brief. http://www. kcl.ac.uk/depsta/law/research/icps/worldbrief/ (acessado em 02/Abr/2008).

2. Christie N. A indústria do controle do crime: a caminho dos GULAGs em estilo ocidental. Rio de Janeiro: Editora Forense; 1998.

3. Freixo M. Prisões, crime organizado e exército de esfarrapados. http://www.pagupsol.org.br (acessado em 14/Fev/2006).

4. Coninx R, Maher D, Reyes H, Grzemska M. Tuberculosis in prisons in countries with high prevalence. BMJ 2000; 320:440-2.

5. Carvalho ML, Valente JG, Assis SG, Vasconcelos AG Perfil dos internos no sistema prisional do Rio de Janeiro: especificidades de gênero no processo de exclusão social. Ciênc Saúde Coletiva 2006; 11: 461-71.
6. Secretaria de Estado de Justiça do Rio de Janeiro. Estudo do perfil biopsicossocial dos apenados que ingressam no sistema penitenciário do Rio de Janeiro. Rio de Janeiro: Superintendência de Saúde, Secretaria de Estado de Justiça do Rio de Janeiro; 2000.

7. Secretaria de Estado de Justiça do Rio de Janeiro. Estudo da relação das DST/AIDS e as drogas no sistema penitenciário do Rio de Janeiro. Rio de Janeiro: Superintendência de Saúde, Secretaria de Estado de Justiça do Rio de Janeiro; 1999.

8. Abrahão RM, Nogueira PA, Malucelli MI. Tuberculosis in county jail prisoners in the western sector of the city of São Paulo, Brazil. Int J Tub Lung Dis 2006; 10:203-8.

9. Oliveira H B, Cardoso JC. Tuberculosis among city jail inmates in Campinas, São Paulo, Brazil. Rev Panam Salud Pública 2004; 15:194-9. 
10. Carvalho ML, Veiga L, Biondi E, Fialho JL, Hanan JL, Leandro EA, et al. Prevalence of HIV-infection in prison system of Rio de Janeiro, Brazil. In: 12th World Aids Conference, Abstracts. Geneva: International AIDS Society; 1998.

11. Sánchez A, Gerhardt G, Natal S, Capone D, Espinola $\mathrm{AB}$, Costa W, et al. Prevalence of pulmonary tuberculosis and comparative evaluation of screening strategies in a Brazilian prison. Int J Tub Lung Dis 2005; 9:633-9.

12. Superintendência de Saúde, Secretaria de Estado de Administração Penitenciária do Rio de Janeiro. Relatório técnico anual do Programa de Controle da Tuberculose. Rio de Janeiro: Secretaria de Estado de Administração Penitenciária do Rio de Janeiro; 2005.

13. Secretaria de Estado de Saúde do Rio de Janeiro. Relatório técnico anual do Programa de Controle da Tuberculose. Rio de Janeiro: Secretaria de Estado de Saúde do Rio de Janeiro; 2005.

14. Sánchez AR, Massari V, Gerhardt G, Barreto AW, Cesconi V, Pires J, et al. A tuberculose nas prisões do Rio de Janeiro, Brasil: uma urgência de saúde pública. Cad Saúde Pública 2005; 23:545-52.

15. Fernandes RCP, Silvany Neto AM, Sena GM, Leal AS, Carneiro CAP, Costa FPM. Trabalho e cárcere: um estudo com agentes penitenciários da Região Metropolitana de Salvador, Brasil. Cad Saúde Pública 2002; 18:807-16.

16. Monteiro S. Qual prevenção? Aids, sexualidade e gênero em uma favela carioca. Rio de Janeiro: Editora Fiocruz; 2002.

17. Goffman E. Manicômios, prisões e conventos. $4^{\mathrm{a}}$ Ed. São Paulo: Editora Perspectiva; 1961.

18. Etzioni A. Organizações complexas. São Paulo: Editora Atlas; 1967.

19. Wacquant L. Que é gueto? Construindo um conceito sociológico. Revista de Sociologia e Política 2004; 23:155-64.

20. Foucault M. Vigiar e punir: nascimento da prisão. Petrópolis: Editora Vozes; 1987.

21. Maheirie K. Constituição do sujeito, subjetividade e identidade. Interações 2002; VII:31-44.

22. Clemmer D. The prison community. Boston: The Christopher Publishing Company; 1940.
23. Lhuilier D, Lemiszeska A. Le choc carcéral. Paris: Bayard; 2001.

24. Lhuilier D. Santé, soins et emprise carcérale. In: Chauvin P, Parizot E, editors. Santé et expériences de soins. Paris: Inserm-Vuibert; 2005.

25. Boltanski L. As classes sociais e o corpo. Rio de Janeiro: Edições Graal; 1979.

26. Amado G, Levy A, editors. La recherche-action; perspectives internationales. Paris: Eska; 2001.

27. Amado G, Ambrose A, editors. The transitional approach to change. London/New York: Karnac Books; 2001.

28. Thiollent M. Metodologia da pesquisa-ação. São Paulo: Cortez Editora; 2003.

29. Benevides R. De vítima a testemunha, de testemunha a cidadão: crises e identidades. In: Rauter C, Passos E, Barros RB, organizadores. Clínica e política: subjetividade e violação dos direitos humanos. Rio de Janeiro: Grupo Tortura Nunca Mais/ Instituto Franco Basaglia/Editora TeCorá; 2002. p. 215-21.

30. Veil C, Lhuilier D. La prison en changement. Paris: Eres; 2000.

31. Dejours C. A banalização da injustiça social. 3a Ed. Rio de Janeiro: Editora FGV; 2000.

32. Vasconcelos ASF. A saúde sob custódia: um estudo sobre agentes de segurança penitenciária no Rio de Janeiro [Dissertação de Mestrado]. Rio de Janeiro: Escola Nacional de Saúde Pública, Fundação Oswaldo Cruz; 2000.

33. Viggiani N. Unhealthy prisons: exploring structural determinants of prison health. Sociol Health Illn 2007; 29:115-35.

34. Condon L, Helk G, Harris F, Powell J, Kemple T, Price S. Users' views of prison health services: a qualitative study. J Adv Nurs 2007; 58:216-26.

35. Caldeira C. Bangu 1: a política do cárcere duro. São Paulo Perspect 2004; 18:87-102.

36. Lira PO, Carvalho GM. A lógica do discurso penitenciário e sua repercussão na constituição do sujeito. Psicol Ciênc Prof 2002; 22:20-31.

Recebido em 15/Mai/2007

Versão final reapresentada em 28/Nov/2007 Aprovado em 10/Jan/2008 